\title{
Differences in Cyberchondria, Internet Addiction, Anxiety Sensitivity, Health Anxiety, and Coronavirus Anxiety Among Students: A Web-Based Comparative Survey
}

\author{
Majd T Mrayyan ${ }^{1,2}$ (D), Sami Al-Rawashdeh ${ }^{1 *}$ (1) , Abdallah Abu Khait $^{1}$ (]), Majdi Rababa ${ }^{3}$ (])
}

${ }^{1}$ Department of Community and Mental Health, Faculty of Nursing, The Hashemite University, P.O. Box 330127, Zarqa 13133, JORDAN

${ }^{2}$ Advanced Nursing Department, F aculty of Nursing, Isra University, P.O. Box 33 and 22 Isra University Office 11622 by Queen Alia International Airport, Amman, JORDAN ${ }^{3}$ Department of Adult Health Nursing, The Hashemite University, P.O. Box 330127, Zarqa 13133, JORDAN

*Corresponding Author: samiy@hu.edu.jo

Citation: Mrayyan MT, Al-Rawashdeh S, Abu Khait A, Rababa M. Differences in Cyberchondria, Internet Addiction, Anxiety Sensitivity, Health Anxiety, and Coronavirus Anxiety Among Students: A Web-Based Comparative Survey. Electron J Gen Med. 2022;19(3):em371. https://doi.org/10.29333/ejgm/11876

ARTICLE INFO

Received: 14 Aug. 2021

Accepted: 8 Jan. 2022

\begin{abstract}
Background: Students' health-related anxiety may exacerbate cyberchondria and internet addiction (IA), especially during pandemics such as the Coronavirus disease 2019 (COVID-19). However, the associations of students' demographic and academic characteristics with cyberchondria, anxiety, and IA have not yet been examined.

Aim: The present study aimed to compare university-level students' scores in cyberchondria, IA, and anxiety (i.e. anxiety sensitivity, health anxiety, and coronavirus anxiety) based on students' characteristics of number of years online, grade point average (GPA), the field of study, year of study, gender, and the availability of Internet access at school.

Methods: Data were collected using valid questionnaires from 143 university-level students via a web-based survey.

Results: Cyberchondria levels were moderate, IA mild, anxiety sensitivity low, health anxiety typical, and coronavirus anxiety functional. No significant differences in the total scores of the compared variables were noted between the compared groups. However, some individual items differed, as follows: 1) Cyberchondria differed according to the student's GPA and the availability of the Internet access at school and 2) IA differed according to all characteristics; and 3) anxiety sensitivity and health anxiety differed according to students' GPA.

Conclusions: The students did not demonstrate high levels of cyberchondria, IA, anxiety sensitivity, or anxiety caused by searching for online health information. Conceptual differences in the concepts can be used in designing interventions to help students prevent and manage such challenges and address avoidance behaviors.
\end{abstract}

Keywords: cyberchondria, internet addiction, anxiety sensitivity, health anxiety, coronavirus anxiety, students

\section{BACKGROUND}

Websites that provide online health-related information are numerous and are commonly used by all people, including university-level students, to search for health conditions or relieve health-related anxieties [1-5]. Further, nursing students frequently use websites as a part of client care [6-9]. However, excessive referral to online health information has increased anxiety $[2,10]$.

Cyberchondria, defined as individuals' health-related anxiety or distress about their health formed from or intensified by their excessive researches of health-related information online [11], has become prevalent and increased concerns about the individuals' mental and physical health [11-13]. Internet addiction (IA), defined as excessive and uncontrolled use of the Internet [14], is a problem that has been linked to cyberchondria and has also become prevalent including among university-level students [2,4,10,14-20]. For instance, the IA prevalence is around $21.2 \%$ in Asian countries [20]. People with psychological problems, including students, have reported a higher likelihood of having excessive online searches and IA [20]. Being male [15], having low income, living in a city, and living in private accommodation have been reported as being predictors of IA among very young adults [20]. Meanwhile, more problematic Internet use has been more evident among female university students than among male students [21].

Online health-related information may induce anxiety, which may cause cyberchondria $[1,4,22]$. Anxiety sensitivity refers to the increased tendency to interpret bodily sensations associated with anxiety as dangerous and/or associated with imminent adverse consequences or harm [23]. Health anxiety is the individual's feelings of worry about their health and that their health is endangered [24]. Both anxiety sensitivity and 
health anxiety are potential risk factors for cyberchondria and IA $[4,12,23,25]$.

The occurrence of unprecedented events may escalate health-related anxiety. For example, anxiety became a widespread problem during the Coronavirus disease 2019 (COVID-19) pandemic [14,18,26,27]. Cyberchondria and IA are relatively emerging issues, but due to the rapid advancement of the Internet, they have become public health issues among different populations, including university-level students $[2,4,13,19,20]$. Few studies have collectively examined the concepts of cyberchondria, IA, anxiety sensitivity, health anxiety, and coronavirus anxiety [2,4,10-12,18-20]. Previous studies have reported IA, anxiety sensitivity, and health anxiety as risk factors for cyberchondria [23,25,28,29]. However, none of these studies has compared all of these concepts among any populations, including students. Further, no study has investigated these concepts among nursing students in Jordan.

Accordingly, this study aimed to describe and compare cyberchondria, IA, anxiety sensitivity, health anxiety, and coronavirus anxiety levels in a sample of Jordanian universitylevel students based on their characteristics. Related studies have been conducted among samples from the general population and were guided by the fear of coronavirus [18]. Only one study has examined the concept of IA among students during the COVID-19 pandemic, reporting that fear of coronavirus is associated with IA, anxiety, and depression among students [14]. Further, studies are needed to collectively examine the concepts of cyberchondria, IA, and their related anxieties, as this may guide the development of interventions to enhance students' understanding and behaviour related to these concepts.

\section{METHODS}

\section{Design and Sample}

This research is part of a large-scale study among Jordanian university-level students and nurses in which the studied concepts were compared according to the student's demographic and academic characteristics. In this crosssectional comparative study, 143 university-level students were recruited using a web-based survey. Convenience and snowball sampling strategies were used to identify eligible participants via Facebook and WhatsApp. Being a university student and able to use web platforms were the only sampling inclusion criteria. The general sampling rule indicated that each variable requires 20-30 participants. Therefore, given that six major variables were explored in this study, the required sample size was 120-180 participants.

\section{Data Collection and Procedures and Human Protection}

In April 2021, data were collected using a web-based selfreport Google forms survey delivered in English. A pilot study was conducted, and no issues were identified. An anonymous link to the survey was posted on Facebook pages and WhatsApp groups to recruit eligible participants. Students were also invited to share the survey link with their eligible contacts. On the front page of the survey, the students were informed that their agreement to respond to the survey constituted their consent to participate in this study. Data were collected over 15 days. On the fourth day of data collection, a reminder was sent to WhatsApp groups and a reminder was posted on Facebook groups. Students were informed that they should complete the survey once only, that their participation was voluntary, and that they had the right to withdraw from the study at any time without consequences. All collected data were coded and kept confidential. The ethics committee at the university where the current study researchers work approved the study (10/72020/2021).

\section{Measures}

\section{Cyberchondria severity scale (CSS)}

The short eight-item version of the CSS was used to measure cyberchondria [30]. This version consists of six items related to the negative and positive consequences associated with searching for health-related information online and two items related to the factors of excessiveness and reassurance seeking [30]. The items are rated on 1="Never" to 5="Always". A mean score $<3$ indicates a low level of cyberchondria, while a score $\geq 3$ indicates a high level of cyberchondria. A moderate (i.e., in the 0.70s) Cronbach's alpha value has been reported for the short eight items CSS [30]. A Cronbach's alpha value of 0.68 was yielded for the eight-item CSS in the current study. This moderate reliability may be attributed to the low number of items measuring a large and heterogeneous construct [31].

\section{Internet addiction test (IAT)}

The IAT is a 20-item measure the presence and severity of symptoms related to pathological internet use [32]. The IAT items are rated on a 6-point Likert scale ranging from $0=$ "not applicable" to 5="always". The total possible score ranges from 0 to 100 , with total scores of 0-30 indicating a normal level of Internet usage and scores of 31-49, 50-79, and 80-100 indicating mild, moderate, and severe levels of IA, respectively [32]. In a meta-analysis study, the overall computed Cronbach's alpha for the original 20-item scale was 0.89 [32]. Among the current study sample, the Cronbach's alpha of the IAT' was 0.85 . In addition to the 20 items, the respondents were asked to respond to extra items related to the Internet Application Checklist, which helps in estimating the percentage of time respondents have utilized different types of online activities or applications (e.g., adult entertainment sites, business email, business surfing, newsrooms, online gaming, and personal email) over the preceding month [32].

\section{Anxiety sensitivity inventory-3 (ASI-3)}

The ASI-3 is an 18-item scale that assesses the tendency to experience health-related anxiety sensitivity [33]. On a 5-point Likert scale, the ASI- 3 items are rated as $0=$ very little, $1=a$ little, 2=some, 3=much, or 4=very much. The total scores are calculated by summing the responses of the 18 items. A total score of 0-17 indicates almost no anxiety sensitivity, 18-35 low sensitivity, 36-53 moderate sensitivity, and 54-72 high sensitivity. Individuals with low anxiety sensitivity are more likely to identify certain matters as harmless and insignificant than individuals with a high anxiety sensitivity level do. The scale items are classified into physical, cognitive, and social subscales. The ASI-3 has good psychometric properties, with very good internal consistency evidenced by Cronbach's alpha values of .92 for the total scale, and $.85, .88$, and .92 for the physical, social, and cognitive subscales, respectively [34]. In the current study, a Cronbach's alpha of 0.84 was yielded for the total scale of ASI-3. 


\section{Health anxiety inventory}

The 18-item Short Health Anxiety Inventory assesses health anxiety independently of physical health status using different statements [35]. Each item is measured on a 4-point Likert scale (0-3), with the statements aimed at assessing worry about health, awareness of bodily sensations or changes, and fear of the consequences of having an illness. Three scores can be calculated from the scale: main score (items 1-14), negative consequences score (items 15-18), and total scores (all the 18 items), with the normal scores among a non-patient control group reported as $9.4( \pm 5.1), 2.8( \pm 2.1)$, and $12.2( \pm 6.2)$ for the main, negative consequences, and total scores, respectively [35]. This inventory was used among students and reported to have very good reliability, with a Cronbach's alpha of .85 [10]. In the current sample, a Cronbach's alpha coefficient of the inventory was 0.86 .

\section{The coronavirus anxiety scale (CAS)}

The five-item CAS screens for dysfunctional anxiety associated with the COVID-19 pandemic [36]. On a 5-point Likert scale, the CAS items are rated as $0=$ "not at all or rare" to 4="nearly every day over the last two weeks". The format of this scale is consistent with the cross-cutting symptom measure of the DSM-5. A total score of $\geq 9$ indicates dysfunctional coronavirus anxiety that might warrant further assessment and treatment [36]. The scale has good internal consistency, as indicated by a Cronbach's alpha of 0.90 [36]. In the current study, the CAS scale Cronbach's alpha was 0.59 , which may have resulted from the low test's total variance or skewed test scores [37].

\section{Data Analyses}

With the significance level set at $<.05$, the Statistical Package for the Social Sciences (SPSS version 25) was used to generate descriptive statistics of means and standard deviations or frequencies and percentages according to the level of measurement for each variable.

The mean scores for scales of cyberchondria, IA, anxiety sensitivity, health anxiety, and coronavirus anxiety and the individual items of these scales were compared based on the subjects' characteristics using the independent samples ttests. The characteristics or variables used for comparisons were:

1. number of years online (years of using the Internet),

2. grade point average (GPA),

3. field of study,

4. year of study,

5. gender, and

6. the availability of internet access at school.

\section{RESULTS}

\section{Subjects' Characteristics}

The majority of the students were under 25 years old, females, senior nursing students, and studying for a bachelor's degree in a scientific field. Further, most students had a very good GPA, over three years of experience searching for information online, and Internet access at school (Table 1).
Table 1. Subjects' characteristics ( $N=143)$

\begin{tabular}{|c|c|}
\hline Characteristics & n (\%) \\
\hline \multicolumn{2}{|l|}{ Field of study } \\
\hline Nursing students & $114(79.7 \%)$ \\
\hline Other students ${ }^{\dagger}$ & $29(20.3 \%)$ \\
\hline \multicolumn{2}{|l|}{ Level of students } \\
\hline Senior $\left(3^{\text {rd }}, 4^{\text {th }}\right.$ Year $)$ & $108(81.2 \%)$ \\
\hline Junior $\left(1^{\text {st }}, 2^{\text {nd }}\right.$ Year $)$ & $25(18.8 \%)$ \\
\hline \multicolumn{2}{|l|}{ Academic stream } \\
\hline Scientific & $129(90.2 \%)$ \\
\hline Humanitarian & $14(9.8 \%)$ \\
\hline \multicolumn{2}{|l|}{ Gender } \\
\hline Male & $39(27.3 \%)$ \\
\hline Female & $104(72.7 \%)$ \\
\hline \multicolumn{2}{|l|}{ Level of education } \\
\hline Diploma & $19(13.3 \%)$ \\
\hline Bachelor's degree & $121(84.6 \%)$ \\
\hline Master and doctorate & $5(3.5 \%)$ \\
\hline \multicolumn{2}{|l|}{ Had internet at school } \\
\hline Yes & $128(89.5 \%)$ \\
\hline No & $15(10.5 \%)$ \\
\hline \multicolumn{2}{|l|}{ Age } \\
\hline$<25$ years & $133(93 \%)$ \\
\hline$\geq 25$ years & $10(7 \%)$ \\
\hline \multicolumn{2}{|l|}{ Years online } \\
\hline$\leq 4$ years & $95(66.4 \%)$ \\
\hline$>4$ years & $48(33.6 \%)$ \\
\hline \multicolumn{2}{|l|}{ GPA } \\
\hline $\mathrm{GPA} \leq 2.5$ & $41(28.7 \%)$ \\
\hline GPA $>2.5$ & $102(71.3 \%)$ \\
\hline
\end{tabular}

Some totals are not $=143$ due to missing data. ${ }^{\dagger}$ Health-related, Science and engineering, Art and educational sciences, and Sport and tourism students

\section{Participants' Main Study Variables Scores}

The mean of cyberchondria scores was 2.55 ( \pm .60$)$, indicating a moderate level of cyberchondria among the participants. The total score of the IAT was $43.14( \pm 13.00)$, indicating a mild level of Internet addiction. The mean of the total anxiety sensitivity scores was $32.06( \pm 8.94)$, indicating a low anxiety sensitivity. The mean health anxiety scores were 14.65 ( \pm 6.24$), 4.42( \pm 2.6)$, and $19.08( \pm 7.8)$ for the main section (items 1-14), negative consequences section (items 15-18), and total scale (all the 18 items), respectively. These scores indicated a typical health anxiety level. Finally, the total coronavirus anxiety score was $7.02( \pm .80)$, indicating functional coronavirus anxiety (Table 2 ).

\section{Comparisons of Cyberchondria Scores}

There were no significant differences in the mean of cyberchondria scores based on years online, GPA, field of study, year of study, gender, or access to the Internet at school as seen from the results. Further analyses were conducted to examine if there were significant differences between the participants (based on the same selected characteristics) in any individual cyberchondria scale items. The results indicated that students with a GPA of 2.5 or less were more overwhelmed by the amount of information available online (item 8 ) than their counterparts did ( $p=.003$, Table 3 ). Further, students who had no Internet access at school felt more frightened than students who had Internet access at school after searching for health information online (item $3, p=.039$ ). Comparisons of cyberchondria individual item scores according to the number of years online, field of study, year of study, or gender showed no significant differences. 
Table 2. Subjects scores on main study variables $(\mathrm{N}=143)$

\begin{tabular}{lcc}
\hline Scale & Possible scores & Actual scores (Mean \pm SD ${ }^{\star}$ ) \\
\hline Mean scores on cyberchondria severity scale & $1-5$ & $2.55 \pm 0.60$ \\
\hline Total internet addiction test scores & $0-100$ \\
\hline Total anxiety sensitivity scale scores & $0-72$ \\
\hline Health anxiety inventory scores & $43.41 \pm 13.0$ \\
\hline Total scores for main section (items 1-14) & $0-42$ \\
\hline$\quad$ Total scores for negative consequences (items 15-18) & $0-12$ \\
\hline$\quad$ Total scores for both sections (all the 18 items) & $0-54$ \\
\hline Coronavirus anxiety scale scores & $0-20$ \\
\hline
\end{tabular}

${ }^{\star}$ SD: Standard deviation

Table 3. Significant differences of individual items of cyberchondria, internet addiction, anxiety sensitivity, health anxiety, and coronavirus anxiety $(\mathrm{N}=143)$

\begin{tabular}{|c|c|c|c|c|}
\hline Characteristics & $\mathbf{M} \pm \mathbf{S D}^{\star}$ & $\mathbf{M} \pm \mathbf{S D}$ & \multirow{2}{*}{ *t-tests } & \multirow{2}{*}{ p-value } \\
\hline Years online & $\leq 4$ years $(n=95)$ & $>4$ years $(n=48)$ & & \\
\hline $\begin{array}{l}\text { Internet addiction: Item 17-How often do you try to cut down the amount of time } \\
\text { you spend online and fail? }\end{array}$ & $2.06(1.03)$ & $1.62(.89)$ & 2.62 & .010 \\
\hline Internet addiction: The extra item-Chat rooms & $1.85(.78)$ & 2.22(.92) & -2.09 & .041 \\
\hline Internet addiction: The extra item-Newsrooms & $1.91(.73)$ & $2.26(.86)$ & -2.16 & .034 \\
\hline Internet addiction: The extra item-Online gaming & $1.88(.83)$ & $2.33(1.12)$ & -2.14 & .037 \\
\hline GPA & $\leq 2.5(n=41)$ & $>2.5(n=102)$ & *t-tests & p-value \\
\hline $\begin{array}{l}\text { Cyberchondria: Item 8-I am overwhelmed by the amount of information I found } \\
\text { online. }\end{array}$ & $2.88(1.45)$ & $2.04(1.01)$ & 3.14 & .003 \\
\hline Internet addiction: The extra item-Instant messaging & $2.18(.73)$ & $1.77(.79)$ & 2.45 & .018 \\
\hline \multicolumn{5}{|l|}{ Anxiety sensitivity inventory: Items } \\
\hline It is important for me not to appear nervous. & $1.60(.97)$ & $1.16(1.14)$ & 2.34 & .022 \\
\hline $\begin{array}{l}\text { When I notice my heart skipping a beat, I worry that something is seriously } \\
\text { wrong with me. }\end{array}$ & $2.26(.77)$ & $1.96(.85)$ & 2.08 & .041 \\
\hline Health anxiety inventory: Item 8-(Being relieved by the doctor assurance) & $1.26(.77)$ & $.96(.85)$ & 2.08 & .041 \\
\hline Field of study & $\begin{array}{l}\text { Nursing } \\
(\mathrm{n}=114)\end{array}$ & Others $(n=29)$ & ${ }^{\star}$ t-tests & p-value \\
\hline $\begin{array}{l}\text { Internet addiction: Item 15-How often do you feel preoccupied with the Internet } \\
\text { when offline or fantasize about being online? }\end{array}$ & $2.25(1.02)$ & $1.83(1.00)$ & 2.01 & .050 \\
\hline $\begin{array}{l}\text { Anxiety sensitivity inventory: Item 8-When I feel pain in my chest, I worry that I } \\
\text { will have a heart attack. }\end{array}$ & $2.38(.90)$ & $1.93(.81)$ & 2.65 & .011 \\
\hline Health anxiety inventory: Item 4-(Resisting thoughts of illness) & $1.33(.83)$ & $.92(.73)$ & 2.15 & .018 \\
\hline Level of students & Senior $(n=108)$ & Junior $(n=25)$ & *t-tests & p-value \\
\hline $\begin{array}{l}\text { Internet addiction: Item 19-How often do you choose to spend more time online } \\
\text { over going out with others? }\end{array}$ & $1.87(.93)$ & $2.44(1.26)$ & -2.09 & .045 \\
\hline $\begin{array}{l}\text { Internet addiction: Item 20-How often do you feel depressed, moody, or nervous } \\
\text { when offline, which goes away once you are back online? }\end{array}$ & $2.39(1.11)$ & $2.92(1.03)$ & -2.23 & .031 \\
\hline Internet addiction: The extra item-Online shopping & $1.83(.78)$ & $2.23(.76)$ & -2.16 & .038 \\
\hline Gender & Male (n=39) & Female $(n=104)$ & *t-tests & p-value \\
\hline $\begin{array}{l}\text { Internet addiction: Item 11-How often do you find yourself anticipating when you } \\
\text { will go online again? }\end{array}$ & $1.87(1.34)$ & $2.50(1.50)$ & -2.41 & .018 \\
\hline The student had internet at school & Yes $(n=128)$ & No $(n=15)$ & *t-tests & p-value \\
\hline Cyberchondria: Item 3-After searching for health information, I felt frightened. & $2.26(.96)$ & $2.67(.96)$ & -2.23 & .039 \\
\hline Internet addiction: Item 14-How often do you lose sleep due to being online? & $2.30(1.15)$ & $2.36(1.20)$ & 2.87 & .009 \\
\hline $\begin{array}{l}\text { Internet addiction: Item 15-How often do you feel preoccupied with the Internet } \\
\text { when offline, or fantasize about being online? }\end{array}$ & $1.84(.96)$ & $2.13(1.07)$ & -2.40 & .026 \\
\hline $\begin{array}{l}\text { Internet addiction: Item 18-How often do you try to hide how long you have been } \\
\text { online? }\end{array}$ & $2.07(1.26)$ & $2.25(1.20)$ & -3.56 & .002 \\
\hline Internet addiction: The extra item-Business email & $1.97(.85)$ & $1.53(.66)$ & 2.15 & .045 \\
\hline
\end{tabular}

\section{Comparisons of IAT Scores}

No significant differences in the mean of the IAT scores based on years online, GPA, the field of study, year of study, gender, or the availability of Internet access at school were noted as seen from the results. As for the participants' scores on the individual items of the scale, there were significant differences based on the selected characteristics (Table 3 ). With regards to the number of years online, students with experience online of four years or under failed to cut down on the amount of time they spent online (item $17, p=.010$ ), but they spent less time on chat rooms (the extra item; $p=.041$ ), newsrooms (the extra item; $p=.034$ ), and online gaming (the extra item; $p=.037$ ). Students with a GPA of 2.5 or less carried out more instant messaging (the extra item; $p=.018$ ) than students with a GPA of over 2.5 did. Compared to their counterparts, nursing students often felt more preoccupied with the Internet when offline (item 15, $p=.050$ ). Further, junior students were more likely than senior students to report often spending more time online over going out with others (item 19, $\mathrm{p}=.045)$, feeling depressed, moody, or nervous when they are offline (item 20, $p=.031$ ), and doing more online shopping (the 
extra item; $p=.038$ ). As compared to male students, female students were more likely to anticipate when they would go online again (item 11, $\mathrm{p}=.018$ ). Students who had no Internet access at school were more likely than their counterparts to report losing sleep after being online (item 14, $p=.009$ ), feeling more preoccupied with the Internet when offline (item 15, $\mathrm{p}=.026$ ), and trying to hide how long they had spent online (item 18, $p=.002$ ). However, these students were less likely to use the Internet for business emails (the extra item; $p=.045$ ).

\section{Comparisons of Anxiety Sensitivity Scores}

There were no significant differences in mean scores of health anxiety sensitivity based on years online, GPA, the field of study, year of study, gender, or access to the Internet at schoolas seen from the results. Concerning the individual scale items, students with a GPA of 2.5 or less were more likely than their counterparts to be sensitive to anxiety; not want to appear nervous in front of others (item 1, p=.022, Table 3), and experience skipping heartbeats that makes them worry that they may have a serious problem (item 12, $\mathrm{p}=.041$ ). Compared to students of other fields, nursing students were more likely to experience anxiety sensitivity to the point of chest pain (item 8 , $\mathrm{p}=.011$ ). There were no other significant differences between the student groups in any of the remaining items.

\section{Comparisons of Health Anxiety Inventory Scores}

There were no significant differences on the mean health anxiety scores between the student groups based on the number of years online, GPA, the field of study, year of study, gender, or access to the Internet at school as seen from the results. As for the individual scale items, students with a GPA of 2.5 or less were more likely than their counterparts to report initially feeling relieved when receiving reassurance from a doctor, but later their worries return (item 8, p=.041, Table 3). Also, compared to students of other fields, nursing students were more likely to report resisting thoughts about illness (item $4, p=.018$ ). There were no other significant differences between the student groups in any remaining items.

\section{Comparisons of Coronavirus Anxiety Scores}

Comparisons of the total mean coronavirus anxiety score and the individual item scores revealed no significant differences between students' groups based on the number of years online, GPA, the field of study, year of study, gender, and access to the Internet at school as seen from the results.

\section{DISCUSSION}

\section{Cyberchondria}

The current study sample had a moderate level of cyberchondria, which is in line with the findings of [38]. Students with a GPA of 2.5 or less were more likely to feel overwhelmed by the amount of information they found online than their counterparts do. This result may be related to the fact that it is not easy for average or below-average students to surf the Internet and comprehend the yielded information. Students with no access to the Internet at school were more likely to report feeling more fearful after searching for health information online than their counterparts do. Although all schools in Jordan provide internet access, this may indicate that not all students use this service. Students who aware of and use the Internet at school are likely to become more frightened after searching for health information online.

\section{Internet Addiction (IA)}

The current study sample had a mild level of IA, which is inconsistent with Guo and colleagues' findings that universitylevel students had moderate to severe levels of IA among university-level students [16]. In addition, it was found that $44 \%$ and $23 \%$ of students were addicted to the Internet and video games, respectively [39]. In the present study, students with experience of being online four years or under failed to cut down on the amount of time they spent online compared to students with over four years of experience. However, they spent less time on online gaming, chat rooms, and newsrooms. In the current age of the Internet and spending more time online, IA is a growing threat. Students who become Internet addicts cannot cut down on the time they spend online. They may surf the Internet out of curiosity rather than carry out recreational activities such as chatting and gaming. Failure to cut down on the amount of time spent online is a maladaptive behavior per se [16]. Given the greater vacant and nonproductive time available to them, students with a GPA of 2.5 or less did instant messaging more than students with a GPA of over 2.5 did, which is also a maladaptive behaviour [16]. Further, nursing students were often more preoccupied with the Internet when offline than students of other fields. The educational requirements of the theoretical and clinical nursing courses are already overwhelming, and nursing students may become anxious about and preoccupied with "missing out" if they have no Internet access. This finding is in agreement with the finding of Kargın and colleagues' that nursing students may experience IA because they rely on the Internet and information technologies in accessing reliable health resources for their clients [17].

Compared to students in other years of study, junior students reported spending more time online than going out with others. This may be because junior students are more likely to have fewer friends and opportunities for socializing. Junior students reported feeling depressed, moody, or nervous when offline and doing more online shopping, indicating maladaptive behaviors [16]. Contrary to the findings of $[15,20]$, female students were more likely to anticipate when they would go online again. Notably, $65 \%$ of the students at the university where this study was conducted were females. Compared to male students, female students in Jordan spend more time at home due to some socio-cultural parameters, and they are more likely to focus while carrying out tasks. This may explain why female students were found to be more active on the Internet, consistent with the findings of [21]. Although all universities in Jordan have Internet access, some students reported that they had no Internet access at their schools, indicating that they were not involved with their university campuses. These students reported that they lost sleep when they had Internet access, often felt more preoccupied with the Internet when offline, and tried to hide how long they had been online, all of which indicate maladaptive behaviors [16].

\section{Anxiety Sensitivity and Health Anxiety}

The students in the present study had a low level of anxiety sensitivity and a typical health anxiety level. These unexpected findings are inconsistent with the findings of [18] and [40, who reported high scores of health anxiety and anxiety symptoms. However, our findings are similar to [41], that only a small 
percentage of their study sample had severe depression, anxiety, or stress during the COVID-19 pandemic. In our study, students with a low level of anxiety sensitivity were more likely to identify certain matters as harmless. Average or belowaverage students (students with a GPA of 2.5 or less) may lack some innovative skills, which may cause them to be more sensitive to anxiety. Thus, it is not surprising that students with a GPA of 2.5 or less were more likely to appear nervous to others and experience skipping heartbeat-related worries than their counterparts do. Nursing students had higher anxiety sensitivity when compared to other students, suggesting that they may be more prone to perceiving certain situations as dangerous [40]. That may explain why they were more likely to experience some physical symptoms such as chest pain.

Anxiety sensitivity is a potential risk factor for health anxiety $[4,12,23,25]$. Moreover, anxiety sensitivity and health anxiety are potential risk factors for cyberchondria and IA $[4,12,23,25]$. Thus, students with a GPA of 2.5 or less were likely to develop health anxiety and have recurring worries even after being reassured by a doctor. Healthcare workers have been reported to be more likely than non-healthcare workers to perceive themselves as likely to become infected at work by the severe acute respiratory syndrome coronavirus (SARS-CoV-2) [42]. In addition, studies in the literature, have reported that although nursing students reported suffering significant stress and anxiety, they have good coping skills [43]. This may apply to the nursing students in the current sample, who reported that most of the time they could resist thoughts of illness. This could imply that their perceived stress was harmless and that they could cope with it, rendering them less prone to health anxiety. In turn, they had low levels of cyberchondria and IA consistent with the findings of $[4,12,23,25]$. These studies reported that high anxiety sensitivity and health anxiety were potential risk factors for cyberchondria, and in turn, the IA.

\section{The Coronavirus Anxiety}

The students in the present study were found to have a functional coronavirus anxiety level. This is inconsistent with $[18,36]$, who reported dysfunctional coronavirus anxiety levels. Another study reported that compared to other age groups, people aged 20-29 years had higher levels of fear COVID-19 pandemic [44] which is similar to the age group of the sample of our study. There were no significant differences in coronavirus anxiety based on the subjects' characteristics, which could mean that coronavirus anxiety is a common problem.

\section{Limitations and Implications of the Findings}

The cross-sectional design employed in the current study does not allow the establishment of causality, which mandates caution in interpreting the results. The convenience and snowball sampling strategies utilized in the current study limit the generalization of the findings. Future research needs to investigate other variables influencing cyberchondria and coronavirus anxiety, especially since the two scales were short and had low-reliability coefficients. Another limitation is that about $80 \%$ of the participants were nursing students, which may have influenced the study results. Most nursing students use online sources to search for medical-related information about different diseases [17]. Further studies that include larger and randomized samples of students from other fields of studies and other universities are needed.
Further, whether blended or completely online, online education has become an integral part of our daily academic lives; it is not just a response to a crisis like the COVID-19 pandemic. Therefore, meeting with students regularly to make them aware of online education and other Internet-related issues is vital. Despite the growing recognition of many psychiatric disorders associated with IA, it is still unclear for students that IA is a psychiatric disorder due to its different assessment dimensions. This necessitates collaboration among parents, instructors, and other authorities to maintain balanced Internet use and investigate psychosocial problems associated with Internet use among students. Seminars and the media can help increase students' awareness of the causes and effects of IA and anxieties as well as how to cope with such psychological problems.

\section{SUMMARY AND CONCLUSIONS}

The participating students in the current study reported moderate cyberchondria, mild IA, low anxiety sensitivity, typical health anxiety, and functional coronavirus anxiety. The researchers found no significant differences in any of the concepts based on the students' characteristics. However, there were significant differences in some individual items of some scales. Significant differences in cyberchondria were found based on GPA and access to the Internet at school. Significant differences in IA were found based on the number of years online, GPA, the field of study, year of study, gender, and access to the Internet at school. Significant differences in anxiety sensitivity were found based on GPA, and significant differences in health anxiety were found based on GPA and field of study. The current study findings can guide the provision of mental health services at universities campuses by facilitating the identification of students at risk of behavioral and psychosocial problems and the provision of effective interventions. Given that the concepts studied are intertwined, conceptual differences should be used to design interventions to help students overcome cyberchondria and IA and manage their related anxieties. The provision of mental health services in university campuses is essential, in addition to the provision of psychosocial support and counseling to address anxiety and IA among students, particularly in these unprecedented times.

Author contributions: MTM: developed the study conception, collected the data, analyzed the data, wrote the abstract, the background, the methods, the results, discussion, limitations, implications, summary, and conclusions, and wrote the first draft of the paper; SA: wrote the second draft of the paper and did the critical revisions and proofread the manuscript; $\mathbf{A K}$ and MR: helped to revise the manuscript, revised the third draft and did a critical revision to the manuscript; MTM and SA: supervised the whole work. All authors have agreed with the results and conclusions.

Funding: No funding source is reported for this study.

Acknowledgements: The researchers would like to acknowledge the input of all subjects who participated in the study.

Ethical statement: The study is approved by the Institutional Review Board of the Hashemite University- Jordan.

Declaration of interest: No conflict of interest is declared by authors.

Data availability statement: The data set associated with this paper can be provided upon reasonable request from the author. 


\section{REFERENCES}

1. Aiken M, Kirwan G. Prognoses for diagnoses: Medical search online and "cyberchondria". BMC Proc 2012;6(Suppl 4):P30. https://doi.org/10.1186/1753-6561-6-s4-p30 PMCid: PMC3426063

2. de la Cuesta J, Catedrilla J, Ebardo R, Limpin L, et al. Personality traits of future nurses and cyberchondria: Findings from an emerging economy. In: 2019 Proceedings of the 27th International Conference on Computers in Education. 2019;2:274-9. Available at: https://animo repository.dlsu.edu.ph/faculty_research/712

3. Deetjen U. The lifestyle paradox: Adverse effects of internet use on self-rated health status. Inf Commun Soc 2017;21(10):1322-36. https://doi.org/10.1080/1369118x. 2017.1313293

4. Selvi Y, Gokce Turan S, Asena Sayin A, Boysan M, Kandeger A. The cyberchondria severity scale (CSS): Validity and reliability study of the Turkish version. Sleep Hypn 2018;20(4):241-6. https://doi.org/10.5350/sleep.hypn.2018. 20.0157

5. Starcevic V, Aboujaoude E. Cyberchondria, cyberbullying, cybersuicide, cybersex: "New" psychopathologies for the 21st century? World Psychiatry 2015;14(1):97-100. https://doi.org/10.1002/wps.20195 PMid:25655165 PMCid: PMC4329904

6. Alving BE, Christensen JB, Thrysøe L. Hospital nurses' information retrieval behaviours in relation to evidence based nursing: A literature review. Health Info Libr J 2018;35(1):3-23. https://doi.org/10.1111/hir.12204 PMid: 29327483

7. Lialiou P, Mantas J. Online information seeking behaviour by nurses and physicians: A cross-sectional study. Stud Health Technol Inform 2016;225:33-7.

8. Scantlebury A, Booth A, Hanley B. Experiences, practices and barriers to accessing health information: A qualitative study. Int J Med Inform 2017;103:103-8. https://doi.org/ 10.1016/j.ijmedinf.2017.04.018 PMid:28550995

9. Zigdon A, Zigdon T, Moran DS. Attitudes of nurses towards searching online for medical information for personal health needs: Cross-sectional questionnaire study. J Med Internet Res 2020;22(3):e16133. https://doi.org/10.2196/ 16133 PMid:32175910 PMCid:PMC710592

10. Rohilla J, Tak P, Jhanwar S, et al. Health anxiety among medical students: A comparison between preclinical and clinical years of training. J Educ Health Promot 2020;9:356. https://doi.org/10.4103/jehp.jehp_491_20 PMid:33575392 PMCid:PMC7871967

11. Starcevic V, Berle D. Cyberchondria: Towards a better understanding of excessive health-related internet use. Expert Rev Neurother 2013;13(2):205-13. https://doi.org/ 10.1586/ern.12.162 PMid:23368807

12. Jokic-Begic N, Lauri Korajlija A, Mikac U. Cyberchondria in the age of COVID-19. PloS ONE 2020;15(12):e0243704. https://doi.org/10.1371/journal.pone.0243704 PMid: 33332400 PMCid:PMC7746178

13. Starcevic V. Cyberchondria: Challenges of problematic online searches for health-related information. Psychother Psychosom 2017;86(3):129-33. https://doi.org/10.1159/ 000465525 PMid:28490037
14. Servidio R, Bartolo MG, Palermiti AL, Costabile A. Fear of COVID-19, depression, anxiety, and their association with internet addiction disorder in a sample of Italian students. J Affect Disord Rep 2021;4:100097. https://doi.org/10.1016/ j.jadr.2021.100097

15. Barmola K. Role of gender in internet addiction among students. In: Gender Equality and Women Empowerment Conference. Jaipur, Rajasthan; 2015. Available at: https://www.researchgate.net/profile/Kailash-Barmola/ publication/333843420

16. Guo W, Tao Y, Li X, et al. Associations of internet addiction severity with psychopathology, serious mental illness, and suicidality: Large-sample cross-sectional study. J Med Internet Res 2020;22(8):e17560. https://doi.org/10.2196/ 17560 PMid:32780029 PMCid:PMC7448182

17. Kargin M, Turkben Polat $\mathrm{H}$, Coskun Simsek D. Evaluation of internet addiction and fear of missing out among nursing students. Perspect Psychiatr Care 2020;56(3):726-31. https://doi.org/10.1111/ppc.12488 PMid:32068267

18. Seyed Hashemi SG, Hosseinnezhad S, Dini S, Griffiths MD, Lin C-Y, Pakpour AH. The mediating effect of the cyberchondria and anxiety sensitivity in the association between problematic internet use, metacognition beliefs, and fear of COVID-19 among Iranian online population. Heliyon 2020;6(10):e05135. https://doi.org/10.1016/ j.heliyon.2020.e05135 PMid:33072911 PMCid:PMC7547399

19. Siste K, Suwartono C, Nasrun MW, et al. Validation study of the Indonesian internet addiction test among adolescents. PLoS ONE 2019;16(2):e0245833. https://doi.org/10.21203/ rs.2.18413/v1 PMCid:PMC6622469

20. Tran BX, Mai HT, Nguyen LH, et al. Vietnamese validation of the short version of internet addiction test. Addict Behav Rep 2017;6(6):45-50. https://doi.org/10.1016/j.abrep.2017. 07.001 PMid:29450235 PMCid:PMC5800578

21. Durak Batigun A, Gor N, Komurcu B, Senkal Erturk I. Cyberchondria scale (CS): Development, validity and reliability study. J Psychiatry Neurolog Sci 2018;31(2):14862. https://doi.org/10.5350/dajpn2018310203

22. Aiken M, Kirwan G, Berry M, O'Boyle CA. The age of cyberchondria. RCSI St Med J 2012;5(1):71-4.

23. Norr AM, Albanese BJ, Oglesby ME, Allan NP, Schmidt NB. Anxiety sensitivity and intolerance of uncertainty as potential risk factors for cyberchondria. J Affect Disord 2015;174:64-9. https://doi.org/10.1016/j.jad.2014.11.023 PMid:25486275

24. Asmundson GJ, Taylor S. It's not all in your head: How worrying about your health could be making you sick-and what you can do about it. Guilford Press; 2005.

25. Norr AM, Allan NP, Boffa JW, Raines AM, Schmidt NB. Validation of the cyberchondria severity scale (CSS): Replication and extension with bifactor modeling. J Anxiety Disord 2015;31:58-64. https://doi.org/10.1016/j.janxdis. 2015.02.001 PMid:25734759

26. Li Y, Wang Y, Jiang J, et al. Psychological distress among health professional students during the COVID-19 outbreak. Psychol Med 2020:1-3. https://doi.org/10.1017/ S0033291720001555 PMid:32389148 PMCid:PMC7225209

27. Taylor S, Landry CA, Paluszek MM, Fergus TA, McKay D, Asmundson GJG. COVID stress syndrome: Concept, structure, and correlates. Depress Anxiety 2020;37(8):70614. https://doi.org/10.1002/da.23071 PMid:32627255 PMCid:PMC7362150 
28. Fergus TA. The cyberchondria severity scale (CSS): An examination of structure and relations with health anxiety in a community sample. J Anxiety Disord 2014;28(6):504-10. https://doi.org/10.1016/j.janxdis.2014.05.006 PMid: 24956357

29. Fergus TA, Spada MM. Cyberchondria: Examining relations with problematic internet use and metacognitive beliefs. Clin Psychol Psychother 2017;24(6):1322-30. https://doi.org/10.1002/cpp.2102 PMid:28621035

30. Jokić-Begić N, Mikac U, Čuržik D, Sangster Jokić C. The development and validation of the short cyberchondria scale (SCS). J Psychopathol Behav Assess 2019;41(4):66276. https://doi.org/10.1007/s10862-019-09744-z

31. Young KS. Caught in the net: How to recognize the signs of internet addiction-and a winning strategy for recovery. John Wiley \& Sons; 1998.

32. Frangos CC, Frangos CC, Sotiropoulos I. A meta-analysis of the reliability of Young's internet addiction test. Proceedings of the World Congress on Engineering. 2012;1:368-71.

33. Taylor S, Zvolensky MJ, Cox BJ, et al. Robust dimensions of anxiety sensitivity: Development and initial validation of the anxiety sensitivity index-3. Psychol Assess 2007;19(2):176-88. https://doi.org/10.1037/1040-3590.19.2. 176 PMid:17563199

34. Capron DW, Norr AM, Macatee RJ, Schmidt NB. Distress tolerance and anxiety sensitivity cognitive concerns: Testing the incremental contributions of affect dysregulation constructs on suicidal Ideation and suicide attempt. Behav Ther 2013;44(3):349-58. https://doi.org/ 10.1016/j.beth.2012.12.002 PMid:23768663

35. Salkovskis PM, Rimes KA, Warwick HMC, Clark DM. The health anxiety inventory: Development and validation of scales for the measurement of health anxiety and hypochondriasis. Psychol Med 2002;32(5):843-53. https:// doi.org/10.1017/s0033291702005822 PMid:12171378

36. Lee SA. Coronavirus anxiety scale: A brief mental health screener for COVID-19 related anxiety. Death Stud 2020;44(7):393-401. https://doi.org/10.1080/07481187. 2020.1748481 PMid:32299304
37. Waltz CF, Strickland OL, Lenz ER. Measurement in nursing and health research. New York: Springer Publishing Company; 2010.

38. McElroy E, Shevlin M. The development and initial validation of the cyberchondria severity scale (CSS). J Anxiety Disord 2014;28(2):259-65. https://doi.org/10.1016/ j.janxdis.2013.12.007 PMid:24508033

39. Mejia CR, Mena LS, Mogollón CA, et al. Compulsive gaming in secondary school students from five Peruvian cities: Usage and addiction to the Pokémon GO game. Electron J Gen Med 2019;16(5):em164. https://doi.org/10.29333/ ejgm/114664

40. Starcevic V, Schimmenti A, Billieux J, Berle D. Cyberchondria in the time of the COVID-19 pandemic. Hum Behav Emerg Technol 2021;3(1):53-62. https://doi.org/10. 1002/hbe2.233 PMid:33363277 PMCid:PMC7753572

41. Quispe-Sancho A, Chambi-Macedo K, Laurel-Vargas V, et al. Depression, Anxiety and stress in health professionals working during the COVID-19 pandemic in Peru: An analytical cross-sectional study. Electron J Gen Med 2021;18(6):em319. https://doi.org/10.29333/ejgm/11210

42. Mejia C, Charri J, Rodriguez-Alarcon J, et al. Perception of possible SARS-CoV-2 infection and associated complications in seven labor sectors in Peru. Electron J Gen Med 2021;18(2):em279. https://doi.org/10.29333/ejgm/ 9730

43. Turner K, McCarthy VL. Stress and anxiety among nursing students: A review of intervention strategies in literature between 2009 and 2015. Nurse Educ Pract 2017;22:21-9. https://doi.org/10.1016/j.nepr.2016.11.002 PMid:27889624

44. Mejia CR, Rodriguez-Alarcon JF, Vera-Gonzales JJ, et al. Fear perception of the COVID-19 pandemic in Peru. Electron J Gen Med 2021;18(3):em285. https://doi.org/ 10.29333/ejgm/9764 